\title{
Saúde mental e trabalho docente
}

Daniela Zanoni Moreira. Câmara Municipal de Gravataí.

Maria Beatriz Rodrigues. Universidade Federal do Rio Grande do Sul.

\section{Resumo}

Este estudo examina causas do absenteísmo por doença de professores em um município do Rio Grande do Sul. Parte de uma pesquisa documental sobre licenças-saúde concedidas durante um ano e a complementa com entrevistas com professores afastados no período. Foram realizadas análises estatísticas dos dados de prontuários de professores afastados, assim como a análise textual das entrevistas. Constatou-se que $50 \%$ dos professores esteve afastado do trabalho por transtornos mentais e comportamentais, segundo a Classificação Internacional de Doenças (CID-10), principalmente transtornos depressivos leves e graves. Os afastamentos podem estar relacionados com a violência nas escolas, além de problemas estruturais e de gestão de recursos, principalmente sobrecarga de trabalho por falta de efetivo, estrutura física inadequada e insuficiente, falta de apoio da gestão, entre outros. A investigação dos afastamentos por doença pode auxiliar na identificação de riscos e na promoção de um ambiente de trabalho mais saudável e seguro para os professores.

Palavras-chave: saúde mental; trabalho docente; adoecimento no trabalho; absenteísmo.

\begin{abstract}
Mental health and teaching. The study addresses the issue of teaching absenteeism in a city of Rio Grande do Sul, Brazil. It departs from a documentary research of sick leaves granted to teachers during a year period and interviews some of these teachers. Statistical analyzes of the data of sick teachers' records were carried out, as well as the textual analysis of the interviews. It was found that $50 \%$ of the teachers were on sick leave for mental and behavioral disorders, as stated by the International Classification of Diseases (ICD-10). Most of these disorders had a depressive nature, mild or severe. Interview data suggest that these leaves could have been caused by violence at school, as well as inadequate physical structure at school and management of resources. The teachers are subject to overcrowded classes, work overload caused by shortage of teachers, lack of support from managers, among others. The study aims to help to identify actions in order to promote a safer work environment and a better quality of life for teachers.
\end{abstract}

Keywords: mental health; teaching; occupational disorders; absenteeism.

\section{Resumen}

La salud mental y la enseñanza. Este estudio examina las posibles causas de ausentismo por causa de salud de los docentes municipales en Rio Grande do Sul. La pesquisa parte de una investigación documental en materia de licencias de salud otorgados a los docentes durante un año complementadas con entrevistas. Se realizaron análisis estadísticos de los datos de prontuarios de profesores alejados, así como el análisis textual de las entrevistas. Se encontró que mitad de los docentes estaba ausente del trabajo para los trastornos mentales y del comportamiento, según la Clasificación Internacional de Enfermedades (CID-10) especialmente la depresión, de formas leves y graves. Los datos sugieren que las desviaciones pueden haber sido causadas por la violencia en las escuelas, así como los problemas estructurales y la organización del trabajo, a sobrecarga por falta de personal, la infraestructura física inadecuada, la falta de apoyo de la gestión, entre otros. La investigación sobre la licencia por enfermedad puede ayudar a los administradores en la identificación y la promoción de un contexto de trabajo más seguro para los docentes. Palabras clave: salud mental; enseñanza; salud ocupacional; absentismo. 
Mudanças na organização do trabalho acompanham desenvolvimentos econômicos, sociais e tecnológicos em sociedades. Nas últimas décadas, o trabaIho tem sofrido novas e importantes transformações, como a racionalização dos processos de trabalho, com consequente redução do emprego, o incremento de atribuições e responsabilidades das ocupações, a flexibilização dos contratos de trabalho, entre outras. Essas mudanças interferem, direta ou indiretamente, em toda a organização social e repercutem na saúde do trabalhador. (Arends, Bultman, Rhenen, Groen, \& Van der Klink, 2013; Merlo, Bottega, \& Perez, 2014).

O levantamento feito pelo Ministério da Previdência Social (MPS) no Primeiro Boletim Quadrimestral de Benefícios por Incapacidade, entre 2000 e 2011, demonstra que os códigos do CID-10 traumatológicos, de riscos ergonômicos e de transtornos mentais estão entre as principais causas de afastamento do trabalho (MPS, 2014). Em outro estudo realizado pelo Instituto Nacional de Seguro Social (INSS), a depressão está entre as quatro causas mais frequentes de absenteísmo e foi responsável por 61.044 afastamentos do trabalho em 2013. Apesar de não ser a única, nem a primeira causa de absenteísmo, a depressão tem crescido em relevância no mundo do trabaIho, com consequências significativas para trabalhadores, governo e sociedade, como demonstra o recorte empírico do presente estudo. A Organização Mundial da Saúde (OMS) estimou que a depressão seria a doença mais comum no mundo na década de 2020 (Collucci, 2014). Dados recentes apontam um número próximo a 300 milhões de pessoas com depressão no mundo em 2015. A depressão está muitas vezes associada a outras patologias, como distúrbios de ansiedade, e é considerada uma das doenças mais incapacitantes e causadora de mortes por suicídio, em torno de 800 mil ao ano. (World Health Organization, 2017).

Este artigo trata do trabalho docente em escolas públicas de um município do Rio Grande do Sul. Os profissionais professores também acompanharam transformações no trabalho educativo, principalmente nas últimas duas décadas. A erosão dos salários, a falta de estrutura material e humana nas escolas, a descontinuidade de anos letivos devido a frequentes greves, a crescente violência nas comunidades, entre outros, simultaneamente produtos e produtores da desvalorização profissional e do decorrente sofrimento no trabalho.
Conforme o Ministério da Educação (ME) a escassez de professores no país, entre 1990 e 2001, era de aproximadamente 250 mil profissionais, para demandas do segundo ciclo do Ensino Fundamental ( $5^{\mathrm{a}}$ a $9^{\mathrm{a}}$ séries) e do Ensino Médio. Este déficit é acentuado nas disciplinas de Língua Portuguesa e Matemática, que têm carga horária semanal expressiva nos currículos escolares e são básicas para a formação dos alunos. A mesma pesquisa demonstrou, baseando-se em salários de professores de diferentes países, que o Brasil é o que menos remunera, mesmo quando comparado com outros países de economia emergente e da América Latina (ME, 2007).

Resultados em classificações mundiais refletem esse cenário, como o Programa Internacional de Avaliação de Desempenho (PISA, 2012 e 2016), aplicado a jovens de 15 anos, em Língua Portuguesa, Matemática e Ciências (Organização para a Cooperação e Desenvolvimento Econômico [OCDE], 2014a; 2015). $\mathrm{O}$ relatório Education at a Glance, demonstrou que o gasto público com educação no Brasil em 2011 foi o equivalente a $19 \%$ do gasto público total ( $6 \%$ do Produto Interno Bruto - PIB). Com esse indicador o país fica acima da média dos países da OCDE, que é de $5 \%$. Porém, quando o indicador é calculado por estudante, o gasto em instituições públicas de todos os níveis educacionais soma 2,985 dólares por aluno, bem abaixo da média da OCDE, de 8,952 dólares (OCDE, 2014b).

Mas os problemas dessa categoria profissional não se resumem aos aspectos econômicos e de desempenho educacional do país. Costa e Germano (2007) afirmam, baseados em dados de pesquisa, que o trabaIho em educação possui características peculiares, que geram estresse e alterações no comportamento dos profissionais envolvidos. Alguns elementos causadores de desconforto no trabalho seriam a tensão própria do ambiente escolar, marcado por relações competitivas entre professores, a constante cobrança por aperfeiçoamento, além das interfaces com a comunidade. Abreu, Coelho e Ribeiro (2016), por meio de dados coletados em entrevistas concluíram que há impactos negativos na prática docente sobre a saúde dos profissionais, principalmente impactos psicológicos. Entre as causas mais relevantes apontadas no estudo está o elevado grau de comprometimento e exigência pessoal, que afetam o trabalho cotidiano.

Gasparini, Barreto e Assunção (2005) chegaram a conclusões semelhantes e acrescentam a relevância das mudanças no papel do professor, que hoje é responsável 
tanto da aprendizagem dos alunos, quanto pela gestão escolar. Outros fatores impactantes no trabalho e na saúde dos professores seriam a carência estrutural e material da maioria das escolas públicas, assim como o baixo salário e pouca valorização da categoria.

Por outro lado, em muitas organizações públicas brasileiras nas áreas responsáveis pela gestão de pessoas há pouca ou nenhuma ênfase no desempenho e nos resultados, faltam mecanismos para o desenvolvimento profissional contínuo, sendo o tempo de serviço o principal critério utilizado para progressões (Schikmann, 2010). A associação entre precariedade das condições e ambiente de trabalho, com as características peculiares do trabalho, além da falta de estrutura de apoio, gera sobrecarga para os professores em atividade.

Faz-se imprescindível o investimento em prevenção de saúde dos professores. Ações preventivas poderiam evitar ou auxiliar na resolução de problemas de saúde e/ou acidentes e, consequentemente, os afastamentos do trabalho. O absenteísmo de professores gera inúmeros problemas, desde a necessidade de substituição, com o treinamento e adaptação de professores substitutos, a descontinuidade do trabalho nas classes, entre outros decorrentes. A qualidade do serviço prestado diminui, gerando descontentamento em toda a comunidade educativa.

Como suporte à gestão de pessoas em organizações públicas foi criado o Serviço Especializado em Engenharia de Segurança e em Medicina do Trabalho (SESMT), em conformidade com o art. 162 da Consolidação das Leis do Trabalho (CLT), sendo obrigatório na estrutura organizacional. O SESMT da Prefeitura em questão realizou um estudo, que revelou um aumento nos afastamentos dos servidores municipais, entre 2010 e 2014. Em 2010 foram registrados 196 licenças-saúde, sendo 42\% de professores, já em 2014, o número de afastados aumentou para 313 , sendo $50 \%$ professores, como pode ser visto na Tabela 1.

Tabela 1. Número e Média Mensal de Servidores e de Professores Afastados do Trabalho por Licença-Saúde - de 2010 A 2014

\begin{tabular}{ccccc}
\hline Ano & $\begin{array}{c}\text { Número de servidores } \\
\text { afastados }\end{array}$ & $\begin{array}{c}\text { Número somente de } \\
\text { professores afastados }\end{array}$ & $\begin{array}{c}\text { Média simples mensal de } \\
\text { servidores afastados }\end{array}$ & $\begin{array}{c}\text { Média simples mensal de } \\
\text { professores afastados }\end{array}$ \\
\hline 2010 & 196 & 83 & 75 & 30 \\
2011 & 227 & 104 & 73 & 34 \\
2012 & 244 & 121 & 104 & 39 \\
2013 & 242 & 129 & 122 & 49 \\
2014 & 313 & 155 & 47 \\
\hline
\end{tabular}

Nota: Fonte: Relatórios do SESMT da Prefeitura Municipal (2015)

A partir dessas constatações, foi realizada uma pesquisa para investigar as causas do absenteísmo por doença dos professores do município. Buscou-se identificar as doenças que majoritariamente causavam os afastamentos do trabalho por licença-saúde e, partindo do levantamento reportado na Tabela 1, foi utilizado como referência o ano de 2014, último ano computado. $O$ estudo utilizou métodos quantitativos e qualitativos, pois associou dados dos prontuários de acompanhamento das licenças-saúde, com entrevistas com professores afastados por doença. Além de estudar o absenteísmo em relação a algumas variáveis como sexo, idade e tempo de serviço, verificou-se a vivência dos professores durante o afastamento e suas percepções sobre possíveis relações de causalidade entre doença e trabalho.
O estudo revelou-se importante para a gestão pública municipal, principalmente no que se refere a: (a) identificação de formas de auxílio ao servidor com problemas de saúde, (b) planejamento de práticas de prevenção de doenças ocupacionais, (c) promoção de um ambiente mais seguro para os servidores. O funcionamento adequado das escolas depende do envolvimento dos trabalhadores e a ausência dos mesmos, principalmente por um período prolongado, acarreta inúmeros problemas de gestão. Conhecendo as causas do absenteísmo a organização pode trabalhar para, concomitantemente, proporcionar o bem estar de seus servidores, reduzir custos, aumentar a qualidade dos serviços prestados à comunidade e a satisfação da população. 


\section{Trabalho e saúde}

O trabalho é relevante para a vida dos indivíduos e tem consequências em suas condições de saúde, tanto físicas quanto mentais. O trabalho é um fator estruturante da subjetividade humana, afeta a relação entre prazer e sofrimento e pode contribuir para a saúde ou para o adoecimento. Dependendo de como é organizado e das condições em que é exercido, o trabalho pode causar até mesmo a morte. Portanto, trabalho não é somente uma forma de sobrevivência, tem um papel social muito relevante (Merlo et al., 2014).

A qualidade de vida no trabalho requer estrutura e recursos apropriados para o bom desenvolvimento das atividades, assim como para a saúde, segurança e satisfação dos indivíduos. A saúde do trabalhador envolve um conjunto complexo de fatores, que também são determinantes para a qualidade de vida: condições adequadas de alimentação, moradia, educação, transporte, lazer e acesso a bens e serviços essenciais. Além disso, é direito de todo o trabalhador a garantia de trabalho em um ambiente saudável, que não gere adoecimento ou morte (Merlo et al., 2014).

Para Marques, Martins e Sobrinho (2011) é importante que o trabalhador perceba contextualmente o trabalho e suas implicações para a saúde, para que possa construir estratégias de enfrentamento, de forma a prevenir processos de sofrimento e adoecimento. Assim sendo, ao discutir saúde do trabalhador deve-se considerar o indivíduo como sujeito de suas ações, agente de sua própria saúde, ativo nas relações com o trabalho e com suas escolhas. Isso não significa atribuir unicamente ao indivíduo a responsabilidade pelo processo de saúde-doença, mas colocá-lo no centro, afinal, "não é uma simples relação de causa e efeito, mas uma complexa rede de relações, encontros, tensões e espaço de luta constante" (Marques et al., 2011, p. 673).

Outro fator importante a considerar na adoção de políticas de prevenção e promoção da saúde é a responsabilidade da gestão nas organizações. Marques et al. (2011) enfatizam a relevância de projetos educacionais ou de adoção de estratégias focados na prevenção nos ambientes de trabalho, como por exemplo, programas de educação continuada, palestras, informativos, exames periódicos, redução de riscos, correções ergonômicas, entre outros significativos à melhora da saúde do trabalhador e ao ganho de produtividade na organização.
Avanços no campo de saúde mental no trabaIho têm ocorrido a partir da compreensão proposta pela Psicodinâmica do Trabalho, que analisa a inter-relação entre saúde mental e trabalho, reconhecendo o trabalho como central e produtor de saúde e doença (Dejours, 1992). Entretanto, ainda existe grande dificuldade na definição de condutas e procedimentos para a investigação e o acompanhamento terapêutico de trabalhadores com sofrimento mental no trabalho. Esse quadro é agravado pela complexidade da evolução dos distúrbios psíquicos, pelas dificuldades na realização de diagnósticos diferenciais e no estabelecimento de nexo causal entre doença e trabalho (Merlo et al., 2014).

Alguns transtornos e doenças relacionados ao trabalho têm sido característicos do trabalho atual, marcado por novos modelos de gestão flexíveis, que solicitam mudanças e pressões constantes na atuação dos profissionais. A tensão resultante está muitas vezes associada a ambientes de trabalho marcados por violência psicológica e, em situações extremas, a assédio moral no trabalho. "O exemplo mais evidente é a utilização do assédio moral como um instrumento banalizado de gestão, na medida em que promove a própria desumanização do indivíduo assediado" (Merlo et al., 2014, pp. 9-10).

Fonseca (2015) associa a informatização às novas exigências do trabalho atual, que altera sobremaneira a solicitação de capacidades do trabalhador, de físicas a intelectuais. Decisões complexas, mediadas e solicitadas pela informática, trazem a urgente necessidade de cuidados com a saúde mental no trabalho. Os riscos laborais podem também decorrer de distorções do poder diretivo do empregador, ou seja, assédio ou invasão do espaço pessoal podem agredir psicológica e mentalmente os trabalhadores. A prevenção da saúde no trabalho, segundo o autor, deve voltar-se prioritariamente ao cuidado com a associação entre a natural competitividade do mercado e o respeito à salubridade psicológica dos trabalhadores.

Para Dejours (1992), o absenteísmo pode materializar-se como uma estratégia defensiva de enfrentamento do preconceito frente ao sofrimento $e$ adoecimento mental. Dessa forma, seria um meio de resistência, de fuga ou de enfrentamento a uma situação de conflito. Ou seja, seria uma busca por equilíbrio diante da insatisfação com o trabalho, uma alternativa ao esgotamento. Pode também representar uma defesa contra a acusação social de que toda a doença é voluntária e, portanto, culpa do sujeito que adoece, que 
sente-se julgado, envergonhado e agravado. Esse seria o círculo vicioso da psicopatologia do trabalho.

O absenteísmo por doença não se relaciona somente ao sujeito que adoece, mas, também às condições presentes no ambiente, à organização do trabalho e às formas de desenvolvimento das atividades laborais. Por exemplo, as causas podem estar relacionadas à supervisão deficiente, ao empobrecimento das tarefas, à falta de incentivo e de motivação e às condições insatisfatórias de trabalho (Alves, Godoy, \& Santana, 2006).

A partir de pesquisas com professores, Zaponi e Silva (2009) elencam algumas possíveis causas do absenteísmo: organização e acompanhamento do trabaIho, excessiva jornada de trabalho, sobrecarga, comportamentos consolidados nas escolas, insatisfação com o salário e benefícios, descontentamento com o local e estrutura de trabalho, relacionamento com colegas, direção ineficiente. Já Abreu, Coelho e Ribeiro (2016) apresentam quatro principais fontes de estresse dos professores: comportamento dos alunos; condições de trabalho; ambiente e clima; nível de supervisão e apoio.

A partir da combinação desses fatores a escola tornou-se um ambiente provocador de tensão, estresse e sofrimento. Como consequência, os profissionais professores sentem-se cada vez menos estimulados pelo trabalho, criando um círculo vicioso de sofrimento, adoecimento e afastamento. "As manifestações de sofrimento surgem mediante vivências de sentimentos de tédio, insatisfação, indignidade, inutilidade, desvalorização e desgaste no trabalho" (Rossi, 2010, p. 306).

\section{A pesquisa - procedimentos metodológicos}

A organização em estudo localiza-se na Região Metropolitana de Porto Alegre, no estado do Rio Grande do Sul. Na cidade há aproximadamente 200 mil habitantes e encontra-se, nos três requisitos avaliados pelo Índice de Desenvolvimento Socioeconômico (IDESE) (Fundação de Economia e Estatística Siegfried Emanuel Heuser, 2012) - educação, renda e saúde como um dos últimos colocados entre os municípios da região (Instituto Brasileiro de Geografia e Estatística [IBGE], 2015a, 2015b). O PIB per capita do município é em torno de 9.500 reais, valor baixo para a região (IBGE, 2016). Estes dados demonstram que a cidade caracteriza-se por baixo nível de desenvolvimento e conta com população econômica e socialmente vulnerável.
Dos 3.270 servidores municipais, 2.718 são estatutários e 552 celetistas. Os professores são 1.569 e representam 58\% dos servidores estatutários e atendem 27 escolas do município. Isso significa cerca de 20 mil estudantes, segundo o Censo Escolar de 2014, do Instituto Nacional de Estudos e Pesquisas Educacionais Anísio Teixeira (INEP). Deste número, 1.227 estão em atividade nas escolas, representando $78 \%$ do total de professores. Esses professores compõem a população de interesse dessa investigação, que não analisou professores lotados em trabalhos administrativos ou cedidos para outras secretarias ou prefeituras.

A pesquisa aborda o absenteísmo por doença, que pode incluir elementos de absenteísmo por patologia profissional e abrangeu os afastamentos do trabalho por licença-saúde, entre janeiro e dezembro de 2014, período em que o SESMT do município estava investigando o aumento considerável de ausências de servidores. A Licença-Saúde (LS) está prevista no Regime Jurídico Único dos Servidores Municipais e é definida como o afastamento do serviço superior a quinze dias ininterruptos.

Nesta pesquisa foram analisados os prontuários dos professores afastados, que contêm os pareceres da Junta de Inspeção de Saúde do Município, além de dados dos servidores, motivos do afastamento, período de licença-saúde e prorrogações necessárias. Os dados coletados na primeira etapa do estudo, de pesquisa documental, foram: idade, sexo, escolaridade, tempo de serviço, período de LS e classificação CID-10 da patologia que gerou o afastamento. Essas informações serviram para elaborar o perfil dos professores afastados e estão organizados e apresentados em figuras e tabelas ao longo do artigo.

Esta pesquisa caracteriza-se como um estudo de caso, pois fornece uma visão global do problema ao identificar fatores que possam ter influenciado os afastamentos por doença, ou que podem ser por eles influenciados. É uma pesquisa descritiva, pois apresenta características do fenômeno absenteísmo por doença, específico de professores, e relaciona variáveis com ele envolvidas, como por exemplo, as características e organização do trabalho, condições e ambiente nas escolas. Utilizou técnicas quantitativas, para o estudo documental dos prontuários e qualitativas, para o levantamento de dados por meio de entrevistas (Gil, 2002; Nique, \& Ladeira, 2014; Vergara, 1998). A análise quantitativa envolveu levantamento estatístico simples, médias e percentuais, a partir de características 
específicas e selecionadas do total dos professores afastados. Os levantamentos foram realizados por meio de planilhas Excel, que facilitaram a sistematização e cruzamento de dados, assim como a construção de figuras e tabelas.

Visando uma análise mais completa dos afastamentos foram realizadas entrevistas semiestruturadas com oito professores, como forma de integrar elementos significativos da percepção dos trabalhadores ao levantamento e discussão dos dados. O critério de seleção dos entrevistados foi aleatório e seguiu, basicamente, a conveniência dos entrevistadores e a disponibilidade dos participantes. A abordagem aos professores afastados geralmente ocorria em suas idas periódicas ao SESMT, para controles da junta de inspeção de saúde ou procedimentos administrativos relacionados às LS. Dessa forma, o perfil dos entrevistados é bastante diversificado, com algumas características que os agrupam, como por exemplo, o fato de terem mais de cinco anos de serviço na prefeitura.

As entrevistas seguiram um roteiro semiestruturado, com questões sobre o afastamento do trabaIho e possíveis causas. O roteiro das entrevistas seguiu os seguintes tópicos: histórico de afastamentos do trabalho; estrutura da escola para os afastamentos; relacionamentos na escola entre colegas, professores e direção; ambiente de trabalho e suas contribuições para os afastamentos; possíveis relações entre organização do trabalho e adoecimento/afastamento; acolhimento após retorno; sugestões para melhoria da qualidade de vida no trabalho dos professores. Todos os professores foram receptivos ao convite para participar na pesquisa, assinaram um termo de consentimento informado, onde concordaram com a gravação, transcrição e divulgação dos dados. A duração das entrevistas foi mediamente de 30 minutos e dependeu da disponibilidade de tempo e condições de saúde dos entrevistados.

Os dados coletados nas entrevistas foram organizados por meio de análise textual proposta por Moraes (2003), método que prevê a desconstrução das entrevistas para examinar em detalhe o material coletado, visando atingir unidades constituintes e enunciados referentes aos fenômenos estudados. Posteriormente, foram estabelecidas relações, ou categorização do material, por meio de construção de conexões entre as unidades de base em conjuntos mais complexos de entendimento, ou categorias de análise. As categorias servem para dar sentido aos dados, estabelecendo tanto relações quanto frequência dos elementos enunciados (Moraes, 2003).

\section{Análise e interpretação dos resultados}

Por meio das informações obtidas com a pesquisa documental foi possível identificar o perfil dos professores afastados do trabalho. Foram registrados 313 servidores afastados, $12 \%$ dos estatutários do município. Entre esses, 155 professores, ou seja, 50\% do total de servidores afastados. Assim sendo, 133 professores estiveram afastados do trabalho em 2014, representando $11 \%$ dos 1.227 professores das escolas do município.

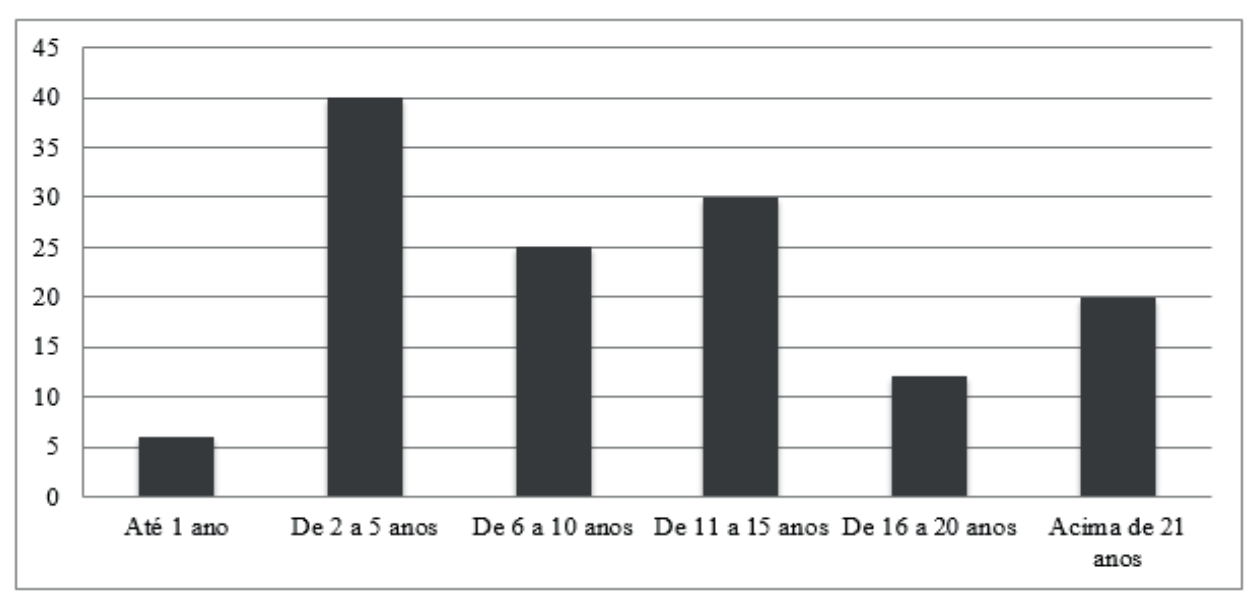

Figura 1. Tempo de Serviço dos Professores Afastados em 2014.

Nota: Fonte: Pastas funcionais dos professores, fornecidas pelo SESMT da Prefeitura (2015). 
Dos professores em licença-saúde $92 \%$ são mulheres. A maioria, 35\%, tem entre 30 e 39 anos, seguido de $28 \%$ na faixa etária entre 40 e 49 anos. Portanto, muitas são mulheres em idade reprodutiva, possivelmente sujeitas a jornadas múltiplas de trabaIho. Quanto à escolaridade, observa-se que a grande parte dos professores possui nível superior, entretanto, a quantidade de professores com ensino médio é também significativa. Os dados sobre o tempo de serviços dos professores apresentam-se bem fragmentados e foram organizados por faixas, conforme Figura 1. Pode-se observar que a concentração dos professores entre dois e cinco anos de trabalho no município. Entretanto, as outras faixas apresentam valores aproximados. Poucos servidores em licença-saúde têm até um ano de serviço.

Quanto ao período de afastamento do trabalho é importante recordar que os casos analisados são por LS, os quais começam a ser considerados após o $16^{\circ}$ dia de absenteísmo. Assim como nas informações sobre idade e tempo de serviço, foi necessária a criação de faixas para agrupar números diversificados. Verificou-se que a maioria dos afastamentos tem um período de até três meses, conforme Figura 2.

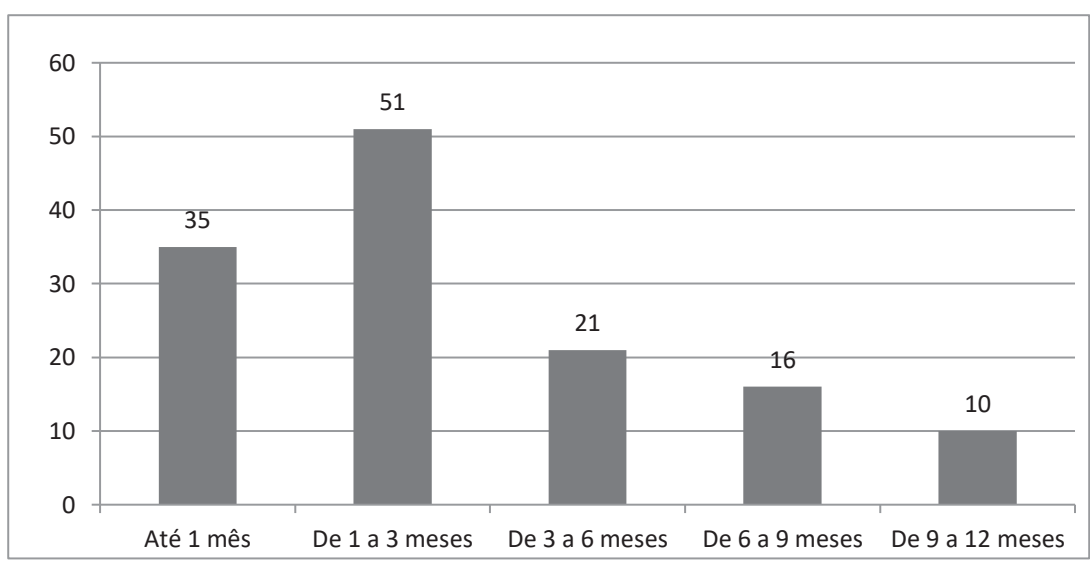

Figura 2. Período de Licença-saúde dos Professores Afastados em 2014.

Nota: Fonte: Pastas funcionais dos professores, fornecidas pelo SESMT da Prefeitura (2015).

Este período de três meses pode ser considerado médio, tendo em vista que há menos afastamentos mais longos. Outra observação importante é que os professores que estão na faixa de nove até doze meses podem estar em licença há mais de um ano, mas como foi selecionado somente o ano de 2014 da pesquisa SESMT, esta informação não pôde ser identificada. No grupo mais representativo, que obteve LS de até três meses, a maioria é de mulheres, na faixa etária de 40 a 49 anos, com tempo de serviço entre dois e cinco anos na Prefeitura. Esses dados são fortes indicativos de doença ocupacional, especialmente concentrados na categoria dos distúrbios comportamentais, sugerindo impactos sobre a permanência no trabalho e o aproveitamento dos alunos. Já o grupo dos professores em afastamento de nove a doze meses, considerado um período longo, que abrange quase todo o ano letivo, a maioria é de mulheres, na faixa entre 50 e 59 anos, com mais de 21 anos de trabalho município. Esses últimos são professores próximos da aposentadoria, no regime especial para professores da Educação Básica e do Ensino Médio, de 25 anos para mulheres e 30 para homens, ou idade de 55 e 60 anos, respectivamente.

A Figura 3 foi elaborada com base nos motivos de LS, conforme CID-10 registrados nos prontuários e apresenta o número de ocorrências das doenças no grupo de professores afastados. Estas doenças estão agrupadas pelas especialidades médicas as quais pertencem: transtornos mentais, neoplasias, lesões, etc. É importante observar que cada professor pode ter sido acometido por mais de uma doença, de diferentes categorias do CID-10, pois o levantamento diz respeito a todos os registros nos prontuários, que somam 139 , número superior ao de professores afastados. Do exame das categorias, constata-se que 67 professores (50\%) foram identificados com transtornos mentais e comportamentais. Em segundo lugar, em número bastante inferior, estão as doenças do sistema osteomuscular e 
do tecido conjuntivo, que acometeram 14 professores (11\%). Em terceiro lugar estão as lesões, que ocasionaram 12 afastamentos (9\%).

No grupo de transtornos mentais e comportamentais, representado pela letra " $F$ " no CID-10, encontram-se doenças psiquiátricas. Aqui também o número de doenças (84) é superior ao número de professores (67), sendo que alguns profissionais foram diagnosticados com mais de uma doença ou transtorno deste grupo. Todas as doenças constantes nos prontuários foram consideradas no estudo, para a verificação de frequências de ocorrência das mesmas entre os professores. A maioria dos professores apresentou transtornos depressivos leves (F32.0), com 11 ocorrências, mas também nove casos de episódios depressivos graves, sem sintomas psicóticos (F32.2). Portanto, a depressão leve ou grave, com 20 professores afastados, representa $24 \%$ das doenças do grupo de saúde mental.

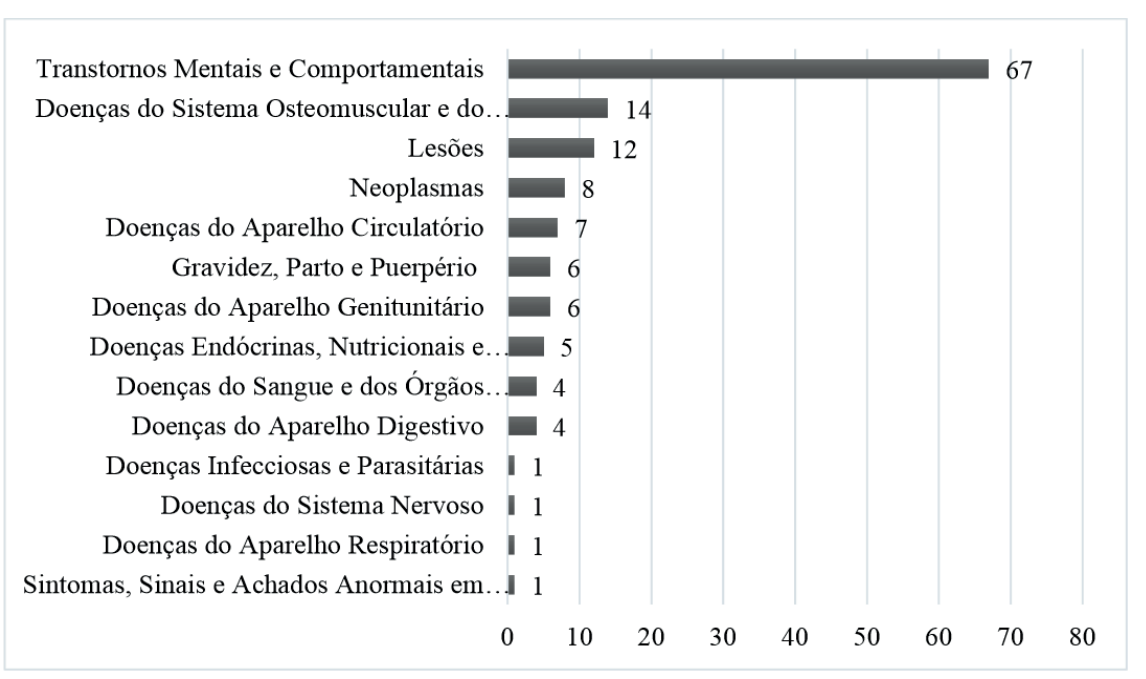

Figura 3. Doenças que Motivaram as Licenças-saúde dos Professores em 2015.

Em segundo lugar, as patologias de transtorno afetivo bipolar (F31.0) e transtorno afetivo bipolar não específico (F32.9), somam 10 ocorrências, ou seja, 12\% de episódios do grupo " $F$ ". Seguem em frequência os diagnósticos de ansiedade generalizada (F41.1), reação aguda ao estresse (F43.0) e transtorno de adaptação (F43.2), que tiveram igualmente cinco ocorrências, totalizando 15 professores afastados, e juntas essas doenças representam $18 \%$ do grupo. Um professor foi acometido pela doença Z73.0, Síndrome de Burnout ou Síndrome do Esgotamento Profissional, do último grupo de classificação do CID-10 (Z00-Z99). Conforme Portaria n 1.339/99 (Ministério da Saúde, 1999), esta síndrome é decorrente de ritmo penoso e outras dificuldades físicas e mentais.

No segundo grupo mais representativo encontram-se doenças do sistema osteomuscular e do tecido conjuntivo, em proporção bem inferior ao primeiro grupo, com 14 casos, $10 \%$ dos professores. Neste grupo encontram-se doenças como dorsalgias, dor ciática e artroses. Dois afastamentos foram decorrentes de acidentes de trabalho, com registro de Comunicação de Acidentes de Trabalho (CAT).

Em terceiro lugar estão as doenças do grupo lesões, S00-T99, que abrangem traumas, fraturas, ferimentos, lesões, entorses, queimaduras, envenenamentos, etc. Neste grupo houve 12 ocorrências, sendo dois casos, de doenças S93.4, entorse e distensão do tornozelo, e S50.0, contusão do cotovelo, classificadas como acidentes de trabalho.

Ao fazer o cruzamento de dados das doenças do grupo transtornos mentais e comportamentais com idade, sexo, tempo de serviço e local de trabalho, constatou-se que a maioria dos professores afastados por esses transtornos estão na faixa etária entre 30 e 39 anos e são do sexo feminino. Também foi verificado que o tempo de serviço está entre dois e cinco anos de trabalho. O maior número de ocorrências de transtornos mentais e comportamentais concentrou-se em quatro escolas: oito em uma delas, seis em duas e cinco em outra. As outras escolas apresentaram número de casos inferior ou igual a quatro. Pode-se dizer que os casos estão distribuídos de forma relativamente 
equilibrada entre as escolas, demonstrando que não ocorreu concentração de adoecimento no trabalho em escolas específicas, o que nos leva a pensar que as situações produtoras de adoecimento estão presentes em todas as escolas do município estudado.

Gasparini et al. (2005) afirmam que dados referentes aos afastamentos não expressam completamente os problemas de saúde vividos pelos sujeitos, assim como, seja difícil estabelecer associações diretas entre esses problemas e o trabalho desenvolvido pelos trabalhadores que adoecem. Entretanto, esses fatores são indicadores que permitem elaborar hipóteses, visando identificar possíveis relações entre adoecimento e condições de trabalho. A fim de explorar mais profundamente os fatores causadores de adoecimento, o levantamento quantitativo foi complementado com entrevistas, que são examinadas no próximo item.

\section{Análise qualitativa das entrevistas}

Os dados analisados nesse item seguem as categorias cridas a partir das respostas dos professores ao roteiro semiestruturado das entrevistas. As falas dos professores foram agrupadas em categorias a partir dos elementos comuns de suas respostas. Apresentamos os tópicos mais relevantes e frequentes nas falas dos professores.

Os entrevistados foram muito categóricos quanto à sobrecarga de trabalho resultante dos constantes afastamentos de professores. As escolas não estão suficientemente organizadas com professores substitutos e muitos do quadro efetivo já cumprem carga horária máxima de 40 horas semanais, atendendo substituições em suas ou em outras escolas. As escolas podem solicitar substitutos à SMED por LS de professores, mas nem sempre são atendidas em suas necessidades de áreas específicas de ensino, devido à escassez de professores disponíveis. As substituições terminam sendo feitas por professores de outras disciplinas, para atendimento emergencial das classes com alguma atividade, consonante ou não com o programa letivo.

Pelos relatos percebe-se a ausência de procedimento padrão para a substituição de ausentes, sendo que em alguns casos o professor substituto atende várias turmas ao mesmo tempo e os alunos permanecem em atividades sem supervisão. Em outros casos, a direção, os responsáveis por projetos de recreação ou pela biblioteca assumem salas de aula, acumulando de tarefas. Essas falas comprovam que as ausências de professores acarretam inúmeros problemas e sobrecarregam os professores restantes podendo, potencialmente, gerar outros afastamentos. Seria importante ter um esquema mais eficiente de remanejo de professores nessas ocasiões, entendendo que os afastamentos por doença têm crescido consideravelmente entre esses profissionais.

As turmas grandes que, em alguns casos, contam inclusive com alunos com deficiência e que exigem um atendimento diferenciado, também geram demanda e sobrecarga de trabalho. Há turmas muito numerosas, que superam os 24 alunos por classe recomendados pela OCDE (2014b). Os professores pesquisados atendem regularmente turmas de 37 a 42 alunos e, para muitos, o trabalho torna-se frustrante e produz esgotamento. Como enfatizado por Fernandes e Barbosa (2014) a docência já é por si só uma atividade de grande envolvimento emocional.

As condições estruturais das escolas e a disponibilidade de materiais para o adequado desenvolvimento do trabalho foram outro ponto muito mencionado entre os entrevistados. Alguns relatam que há escolas com boa estrutura física e material, principalmente com espaços adequados e presença de bibliotecas equipadas, enquanto a maioria aponta problemas de infraestrutura. Alguns problemas assinalados: laboratórios de informática sem internet; prédios velhos de madeira sem conservação, ambientes sujeitos à chuva, frio e intempéries; ausência ou precariedade de quadras de esportes; pátios ou espaços recreativos com obstáculos perigosos; entre outros problemas que prejudicam o trabalho e põem em risco professores e alunos.

A violência é presença constante nas escolas. Três dos entrevistados relataram ter sofrido ameaças diretas de alunos e pais e outros afirmaram presenciar cotidianamente situações de abuso no local de trabalho. Uma entrevistada referiu um episódio de humilhação, ao ser desautorizada por sua chefia na frente de pais e alunos. Outra colocou da dificuldade de relacionamento com a comunidade em geral, violenta e invasiva. Outro professor contou da ameaça de morte que recebeu de parte de um aluno. Professores atribuem muitos desses problemas ao tráfico e consumo de drogas nas escolas e arredores. Sendo um problema difuso nas comunidades e difícil de ser controlado pelas escolas, o ambiente "permissivo" às drogas perpetua casos de abuso e violência, provocando medo e insegurança nos professores. Pesquisas realizadas em escolas de várias capitais brasileiras demonstraram que parte significativa dos 
entrevistados pensa que o ambiente escolar seja tanto ou mais violento quanto o entorno. Pode-se considerar que a escola abriga e reproduz a violência (Abramovay, 2002; Abramovay \& Ruas, 2003).

A maioria dos entrevistados respondeu afirmativamente quando questionada sobre relações causais entre o trabalho que realizam e os afastamentos. Alguns professores relataram situações que teriam contribuído para seus afastamentos: retirada de posições e situações cômodas de trabalho, como por exemplo, troca de disciplina ou de local de atividade; adoecimento físico pelas condições do ambiente laboral, como frio ou contágio por doenças infectocontagiosas; ameaças e testemunho de violências; pressões e estresse; falta de condições físicas e materiais para o desenvolvimento do trabalho, entre as mais mencionadas.

Percebe-se nas colocações de muitos professores afastados o receio com o estigma da doença mental. Muitos referem que colegas e chefias, por não verem objetivamente a doença psíquica a associam com preguiça, ou má vontade, os olham com desconfiança e não acreditam no sofrimento. Essa sensação pode provocar o agravamento da doença, pois muitos adiam o afastamento do trabalho, para evitar o julgamento dos colegas. $\mathrm{O}$ isolamento e o sofrimento crescem, podendo ocorrer casos de suicídio, em uma espécie de "patologia da solidão" (Merlo et al., 2014). Além disso, muitos professores reconhecem a inabilidade da gestão das escolas para lidar com procedimentos administrativos em casos de doenças profissionais, pois os diretores de escolas são professores em exercício de gestão, sem experiência ou formação para esse papel.

\section{Considerações finais}

No mundo são crescentes os afastamentos do trabalho por adoecimento psíquico. A OMS estima que a depressão será a doença mais comum no mundo nas próximas décadas, o que traz grande preocupação para governos, empresas e trabalhadores (Collucci, 2014). Por mais que seja difícil estabelecer uma relação direta entre doença e trabalho, estudos como o apresentado, entre outros prévios, demonstram que o trabalho tem um papel importante na saúde dos indivíduos, tanto negativo quanto positivo. Autores enfatizam que nem sempre o trabalho é fonte de doença ou infelicidade, mas pode (e deve?) ser fonte de saúde e prazer; entretanto, essas possibilidades dependem das condições nas quais o mesmo é realizado (Dejours, 1992; Merlo et al.,
2014), A qualidade de vida no trabalho, a segurança, a satisfação dos trabalhadores, podem resultar em um bom desempenho e em saúde para o trabalhador.

Analisando a saúde ocupacional dos docentes pesquisados é possível verificar que, por características e organização do trabalho, existe um sistema gerador de patologias, principalmente causador de adoecimento por transtornos mentais e comportamentais. Os relatos de professores sugerem inúmeros problemas que poderiam ocasionar sofrimento e gerar adoecimento: desvalorização e pouco reconhecimento social do professor, baixa remuneração, gestão despreparada, turmas superlotadas, inexistência de pausas, infraestrutura precária, carência de recursos materiais e humanos e violência nas escolas. Tudo isso sem que haja um espaço coletivo de discussão, identificação e encaminhamento de soluções nas escolas.

No presente estudo $50 \%$ dos professores foram afastados por transtornos mentais e comportamentais, sendo que aproximadamente metade destes, $24 \%$ por diagnóstico de depressão, $12 \%$ por transtorno bipolar, seguidos por reação aguda ao estresse, transtorno de adaptação e ansiedade generalizada e Síndrome de Burnout. Esses dados confirmam conclusões de estudos anteriores de que as principais causas do absenteísmo por doença estão no grupo de transtornos mentais e comportamentais do CID-10, com 50\% dos afastamentos no estudo de Batista, Carlotto e Moreira (2013) e aproximadamente $20 \%$ no estudo de Costa e Germano (2007). A doença mais frequente é a depressão.

Existe uma necessidade premente de atenção à saúde mental dos professores. Ao verificar que estas moléstias estão associadas ao ambiente laboral, faz-se crucial pensar em melhorias nas condições de trabalho destes profissionais, principalmente no que se refere à segurança, à ampliação do efetivo nas escolas, ao apoio institucional. Algumas propostas de solução poderiam envolver jornadas de trabalho menos intensas e extensas, maior autonomia, menos sobrecarga por atividades extraclasse, como possíveis formas para aliviar a tensão a que os professores estão continuamente sujeitos. Além disso, para garantir a efetividade dessas ações seria importante investir na formação e qualificação de gestores, pouco preparados para o importante papel que exercem nesse contexto, pois "oscilam entre a possibilidade de serem agentes da organização e atores do cotidiano" (Martins, 2007, p. 728).

Os professores relataram o preconceito com a doença mental, que provoca, por um lado, a rejeição 
de colegas e chefias e, por outro, o agravamento da situação patológica do doente, que posterga o afastamento temendo ser objeto de preconceitos e retaliações. Associa-se a isso o ambiente de violência e degradação de muitas comunidades, os professores sentem-se ameaçados no ambiente de trabalho, que deveria primar por condições adequadas ao exercício profissional. A violência nas escolas está associada ao uso e tráfico de drogas, atuação de gangues, porte ilegal de armas, desrespeito generalizado e permissividade. As zonas que circundam as escolas de periferia são prodígios em violência de todos os tipos, mas não é somente o ambiente externo que circunscreve a violência. Essas informações são confirmadas por pesquisas, Abramovay, 2002 e Abramovay e Ruas, 2003 para citar algumas, sendo algo recorrente em escolas das periferias de metrópoles brasileiras.

Como vimos na pesquisa aqui relatada, as condições de trabalho dos professores está distante do adequado. Professores responsáveis por formar novas gerações de alunos adoecem no trabalho, por falta de estrutura física e material, por violência nas escolas e por desrespeito profissional. Esse quadro é muito sério e tem se agravado. Seria importante investigar medidas que tenham sido tomadas para a melhoria dessa situação e, mais do que isso, tomar decisões efetivas, dentro e fora das escolas, para mudar essa realidade. O tema é de grande importância para o aperfeiçoamento da educação brasileira e das condições de trabalho dos professores. Nós associamos a pesquisas sobre o tema referido, apesar de reconhecermos as limitações do presente estudo, a uma específica realidade (Martins, 2007). Sugere-se que mais pesquisas sejam realizadas sobre temas e situações relacionadas à saúde mental no trabalho docente, como forma de conhecer as realidades das escolas e propiciar intervenções para que sejam melhoradas.

É fundamental a valorização dos professores, para que as instituições de ensino possam cumprir o papel de formação de cidadãos para um futuro melhor, em uma sociedade mais justa, responsável e ética. A educação é um dos elementos de acesso e exercício de cidadania, além de favorecer a inclusão pessoal e profissional. Porém, o que encontramos na maioria das escolas públicas são estruturas precárias, abandonadas, incapazes de fazer frente à situação caótica em que vivem. Essas organizações favorecem o adoecimento de seus trabaIhadores e, com certeza, não estão cumprindo plenamente o seu papel de formação. Professores se afastam do trabalho, devido a um círculo vicioso de frustrações e de perpetuação da exclusão aqui evidenciada.

\section{Referências}

Abramovay, M. (2002). Escola e violência. Brasília: UNESCO. [versão em pdf]. Recuperado e http://unesdoc.unesco.org/ images/0012/001287/128717por.pdf.

Abramovay, M., \& Ruas, M. (2003). Violências nas escolas: versão resumida. Brasília: UNESCO. [versão em pdf]. Recuperado de http:// unesdoc.unesco.org/images/0013/001339/133967por.pdf.

Abreu, M., Coelho, M., \& Ribeiro, J. (2016). Percepção de professores universitários sobre as repercussões do seu trabalho na própria saúde. Revista Brasileira de Pós-Graduação. 13(31), 1-19. doi: 10.21713/2358-2332.2016.v13.1155

Alves, M., Godoy, S., \& Santana, D. (2006). Motivos de licenças médicas em um hospital de urgência-emergência. Revista Brasileira de Enfermagem, 59(2), 195-200. doi: 10.1590/ S0034-71672006000200014

Arends, I., Bultmann, U., Rhenen, W., Groen, H., \& Van der Klink, J. J. L. (2013). Economic evaluation of a problem solving intervention to prevent recurrent sickness absence in workers with Common Mental Disorders. PloS ONE, 8(8), e71937. doi: 10.1371/journal. pone. 0071937

Batista, J., Carlotto, M., \& Moreira, A., (2013). Depressão como causa de afastamento do trabalho: um estudo com professores do Ensino Fundamental. Psico, 44(2), 257-262. Recuperado de http://revistaseletronicas. pucrs.br/ojs/index.php/revistapsico/article/ view/11551

Collucci, C. (2014, março). Depressão é uma das principais causas de afastamento. Folha de São Paulo. Recuperado de http://www1.folha. uol.com.br/fsp/especial/158637-depressao-e-uma-das-principaiscausas-de-afastamento.shtml

Costa, P., \& Germano, A. (2007). Afastamento dos professores de $5^{\mathrm{a}}$ à $8^{\text {a }}$ séries da rede municipal de Ipatinga da sala de aula: principais causadores. In Centro Universitário de Caratinga (Org.), Anais do VI Congresso de Letras: Linguagem e Cultura: Múltiplos Olhares. Recuperado de http://bibliotecadigital.unec.edu.br/ojs/index.php/ unec03/index

Dejours, C. (1992). A loucura do trabalho. São Paulo: Cortez.

Fernandes, M., \& Barbosa, A. (2014). O trabalho docente na rede pública do estado de São Paulo: apontamentos iniciais para a discussão da jornada de trabalho. Práxis Educacional, 10(17), 117-142. Recuperado de http://hdl.handle.net/11449/125053

Fonseca, R. (2015). Assédio moral organizacional: o poder diretivo pode adoecer e causar feridas. In Gediel et al. (Orgs.), Estado, poder e assédio: relações de trabalho na Administração Pública (pp. 31-52). Curitiba: Kairós Edições.

Fundação de Economia e Estatística Siegfried Emanuel Heuser (2012). Índice de Desenvolvimento Socioeconômico (Idese). Recuperado de http://www.fee.rs.gov.br/wp-content/uploads/2014/12/20141217textoidese-site-2011-2012-revisado-2.pdf

Gasparini, S., Barreto, S., \& Assunção, A. (2005). O professor, as condições de trabalho e os efeitos sobre sua saúde. Revista Educação e Pesquisa, 31(2), 189-199. doi: 10.1590/ S1517-97022005000200003

Gil, A. (2002). Como elaborar projetos de pesquisa. São Paulo: Atlas. 
Instituto Brasileiro de Geografia e Estatística (2015a). Biblioteca. Recuperado de http://biblioteca.ibge.gov.br

Instituto Brasileiro de Geografia e Estatística (2015b). Cidades. Recuperado de http://www.cidades.ibge.gov.br/xtras/home.php

Instituto Brasileiro de Geografia e Estatística (2016). Índice de Desenvolvimento Humano Municipal. Recuperado de http://cod. ibge.gov.br/233OL

Instituto Nacional de Estudos e Pesquisas Educacionais Anísio Teixeira (2014). Censo Escolar 2014. Recuperado de http://portal.inep.gov. br/basica-censo-escolar-matricula

Marques, S., Martins, G., \& Sobrinho, O. (2011). Saúde, trabalho e subjetividade: absenteísmo-doença de trabalhadores em uma universidade pública. Cadernos EBAPE, 9(ed. esp.), 669-680. doi: 10.1590/S1679-3951.2011000600012

Martins, A. (2007). Gestão de escola pública: análise de uma proposta de intervenção. Cadernos de Pesquisa, 7(132), 711-730. doi: 10.1590/ S0100-15742007000300010

Merlo, A., Bottega, C., \& Perez, K. (2014). Atenção ao sofrimento e ao adoecimento psíquico do trabalhador e da trabalhadora: cartilha para profissionais do Sistema Único de Saúde. Porto Alegre: Evangraf.

Ministério da Educação (2007). Conselho Nacional de Educação. Escassez de professores no ensino médio: propostas estruturais e emergenciais. Recuperado de http://portal.mec.gov.br/cne/arquivos/ pdf/escassez1.pdf

Ministério da Previdência Social (2014). 1o boletim quadrimestral sobre benefícios por incapacidade. Brasília, DF. Recuperado de http://sa.previdencia.gov.br/site/2017/04/1\%C2\%BA-boletimquadrimestral.pdf

Ministério da Saúde (1999). Portaria no 1339, de 18 de novembro de 1999. Institui a Lista de Doenças relacionadas ao Trabalho, a ser adotada como referência dos agravos originados no processo de trabalho no Sistema Único de Saúde, para uso clínico e epidemiológico. Recuperado de http://bvsms.saude.gov.br/bvs/saudelegis/gm/1999/ prt1339_18_11_1999.html
Moraes, R. (2003). Uma tempestade de luz: a compreensão possibilitada pela análise textual discursiva. Revista Ciência \& Educação, 9(2), 191-211. doi: 10.1590/S1516-73132003000200004

Nique, W., \& Ladeira, W. (2014). Pesquisa de Marketing: uma orientação para o mercado brasileiro. São Paulo: Atlas.

Organização para Cooperação e Desenvolvimento Econômico (2014a). PISA 2012. Resultsin focus: what 15-years-old know and what they can do with they know. Paris. Recuperado de http://www.oecd.org/ pisa/keyfindings/pisa-2012-results-overview.pdf

Organização para Cooperação e Desenvolvimento Econômico (2014b). Relatório Education at a glance 2014: nota sobre o país. Paris. Recuperado de http://www.oecd.org/edu/Brazil-EAG2014-CountryNote-portuguese.pdf

Organização para Cooperação e Desenvolvimento Econômico (2015). Programme for International Students Assessment (PISA). Results from PISA 2015. Recuperado de http://www.oecd.org/pisa/ PISA-2015-Brazil-PRT.pdf

Organização Mundial da Saúde (1997). Classificação Estatística Internacional de Doenças e Problemas Relacionados à Saúde CID-10 (10ae ed.) São Paulo: Editora da Universidade de São Paulo

Rossi, E. (2010). Psicodinâmica do trabalho: um olhar sobre a saúde do trabalhador. In M. Pantoja, M. Camões, \& S. Bergue (Orgs.), Gestão de Pessoas: bases teóricas e experiências no setor público (Capítulo VI, pp. 301-315). Brasília: ENAP.

Vergara, S. (1998). Projetos e relatórios de pesquisa em Administração. São Paulo: Atlas.

World Health Organization (2017). Depression and other common menta disorders: global health estimates. Recuperado de http://apps.who. int/iris/bitstream/10665/254610/1/WHO-MSD-MER-2017.2-eng.pdf

Zaponi, M., \& Silva, R. (2009). Absenteísmo docente: uma análise diagnóstica da Rede Estadual de Ensino de Pernambuco. In Associação Nacional de Política e Administração da Educação - ANPAE (Org.), Anais do XXIV Simpósio Brasileiro de Política e Administração da Educação, Cadernos Anpae no 08, Vitória, ES. Recuperado de http://www.anpae.org.br/congressos_antigos/ simposio2009/215b.pdf

Daniela Zanoni Moreira, Administradora de Empresas pela Escola de Administração da Universidade Federal do Rio Grande do Sul (EA-UFRGS), é Assessora Parlamentar da Câmara Municipal de Gravataí (CMG-RS). Endereço para correspondência: Rua Washington Luiz 855, 90010-460, Porto Alegre, RS. Telefones: (51) 3308-3834/ (51) 99141-8515. E-mail: danielazmoreira@yahoo.com.br

Maria Beatriz Rodrigues, Pós-doutorado em Educação pelo Programa de Pós-Graduação em Informática da Educação da Universidade Federal do Rio Grande do Sul (PPGIE-UFRGS), PhD em Development Studies pelo Institute of Development Studies, Sussex University, Reino Unido, é Professora do Programa de Pós-Graduação da Escola de Administração da Universidade Federal do Rio Grande do Sul (PPGA-EA-UFRGS). E-mail: beatriz.rodrigues@ufrgs.br 